\title{
Digital Clubbing may be a Clinical Sign of Gastrointestinal Kaposi Sarcoma in a HIV-Positive Patient
}

\author{
Felipe Tavares Rodrigues, Marcos Roberto Pereira Cardozo, \\ Ana Lucia Taboada Gjorup, Julio Cesar Tolentino Junior \\ Escola de Medicina e Cirurgia do Rio de Janeiro, Hospital Universitário \\ Gaffrée e Guinle, Universidade Federal do Estado do Rio de Janeiro \\ (UNIRIO), Rio de Janeiro, Brazil.
}

Corresponding Author Felipe Tavares Rodrigues

Mobile:

$+55-21-2204-2746$

E mail:

medftr@yahoo.com.br

Key words: Digital clubbing , HIV
A 48-year-old human immunodeficiency virus (HIV) positive male patient presented with two months history of intermittent left iliac fossa pain, tenesmus, and gradual enlargement of fingertips. He denied diarrhea, cough, fever and weight loss. Home medications included recent initiation of highly active antiretroviral therapy (HAART).

Seven months before, he had been hospitalized for two months with cutaneous Kaposi sarcoma diagnosed by skin biopsy, with no other AIDSrelated illness. His cutaneous lesions were healed with chemotherapy. After the HAART had been started, the absolute CD4 cell count increased to 550 cells $/ \mu \mathrm{L}$, and HIV-RNA became undetectable. As he had episodes of abdominal pain and diarrhea, colonoscopy and endoscopy were performed during hospitalization. These endoscopic exams revealed inflammatory lesions, and ulcered nodules in gastric, ileal, colonic and retal regions. Typical volcano-like reddish and bleeding masses with central umbilication and ulceration were seen ${ }^{1}$. Biopsy specimens obtained from these lesions showed eosinophils and lymphoplasmocytic cell infiltrates. Cryptosporidium oocyst was not found and a culture for bacteria, mycobacteria and fungi were negative.

A recent digital clubbing and edema in lower limbs were observed. Biochemical markers were normal, including amylase, lipase, albumin, and liver function panel. Evaluation with computed tomography imaging of the thorax/abdomen/pelvis was unremarkable. After five months of the first endoscopic examination performed during his hospitalization, a new endoscopy and colonoscopy with biopsy were ordered. The biopsy specimens revealed whorls of spindleshaped cells and neovascularization with small-vessel proliferation suggestive of Kaposi sarcoma (KS). Immunohistochemical testing for human herpes virus 8 (HHV-8) was positive, supporting the KS diagnosis. The differential diagnosis of this case could have been Crohn Disease, induced by an immune reconstitution inflammatory syndrome (IRIS), after HAART start; or a chronic viral, bacterial or parasitary colitis.

Kaposi Sarcoma (KS) physiopathology includes HHV-8 mutagenic potential to create an angiogenic tumor and hypervascularity [1]. About $50 \%$ of gastrointestinal (GI) Kaposi Sarcoma cases are reported in HIV patients with cutaneous manifestations of KS [1,2]. Digital clubbing (DC) is characterized by a focal bulbous enlargement of the terminal segments of the fingers and toes due to the proliferation of connective tissue between the nail matrix and the distal phalanx. Although clubbed fingers are mostly asymptomatic, it often predicts the presence of some severe underlying diseases [3]. There are only a few reports linking HIV infection and clubbing [4]. However, direct linking of HIV to 
clubbing is still a matter of controversy. Clubbing in HIV-infected patients has been attributed to concomitant pulmonary, neoplasic and hepatic illness $[\mathbf{5 , 6}]$. However, in the present patient the arterial blood gas, computed tomography and magnetic resonance imaging of the thorax/abdomen/pelvis, echocardiogram, pulmonary function test and specific laboratory tests were normal. As in the patient the only disease detected was GI KS, his digital clubbing may be related to gastrointestinal KS. The patient had no Intestinal Inflammatory Disease history before AIDS diagnosis, so that IRIS occurrence would be improbable. Increase of proinflammatory cytokines and Vascular Endothelial Growth Factor in HIV can lead to DC and KS development [6] The majority of GI KS cases remain underdiagnosed; these data indicate the importance of digital clubbing among the large range of HIV-positive patients nail manifestations [4], now including patients with gastrointestinal disorders, as our case of Kaposi Sarcoma disease.

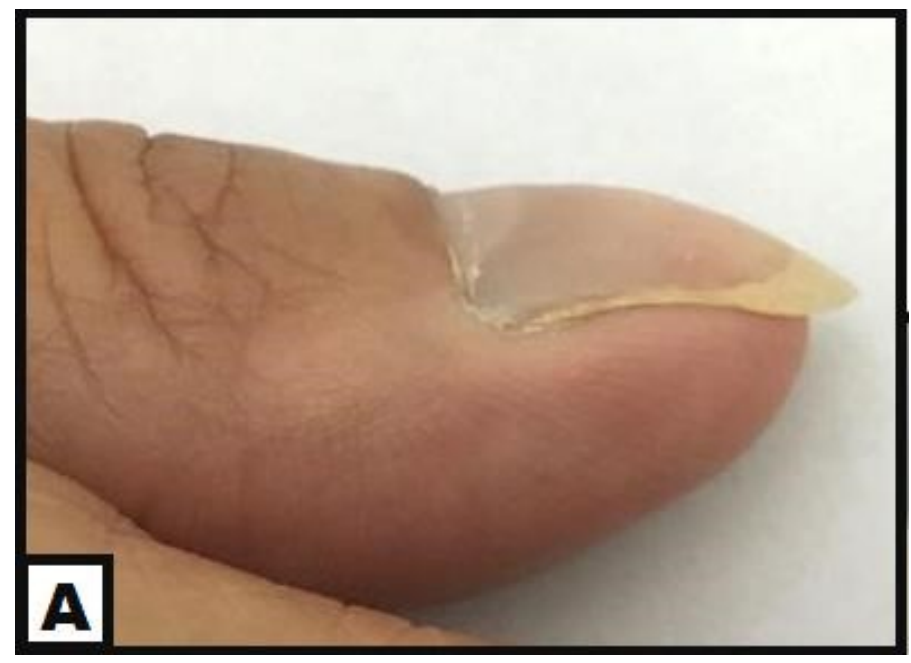

Figure A: Digital clubbing

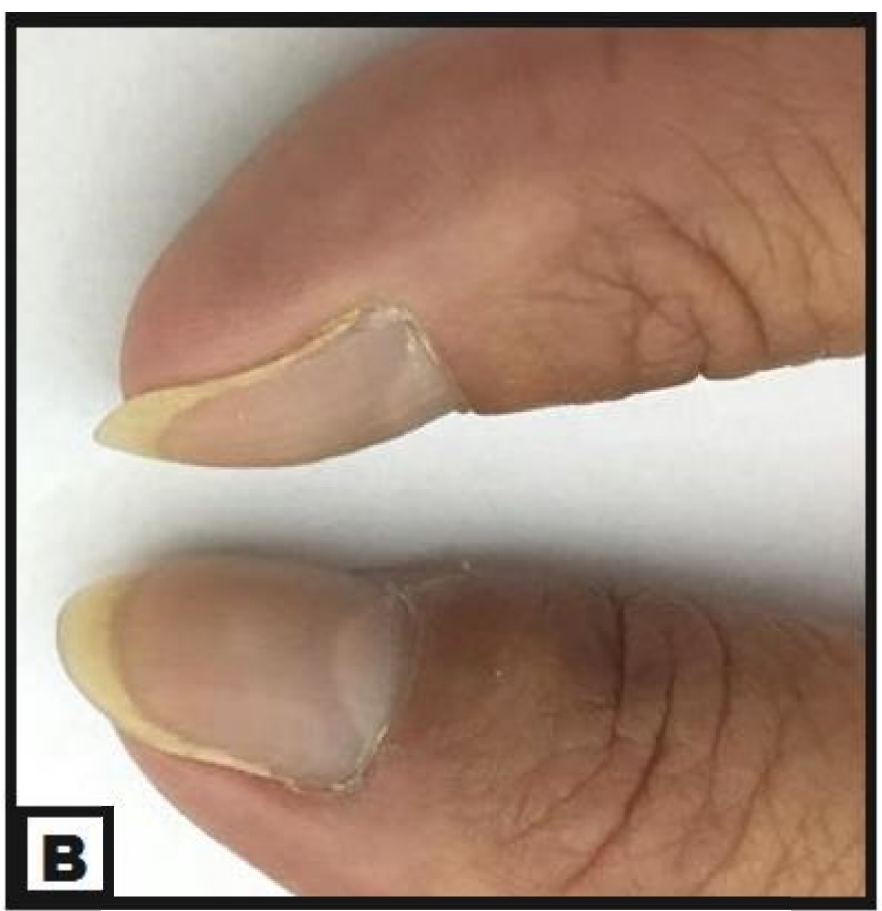

Figure B: Bulbous enlargement of soft parts of the terminal phalanges 


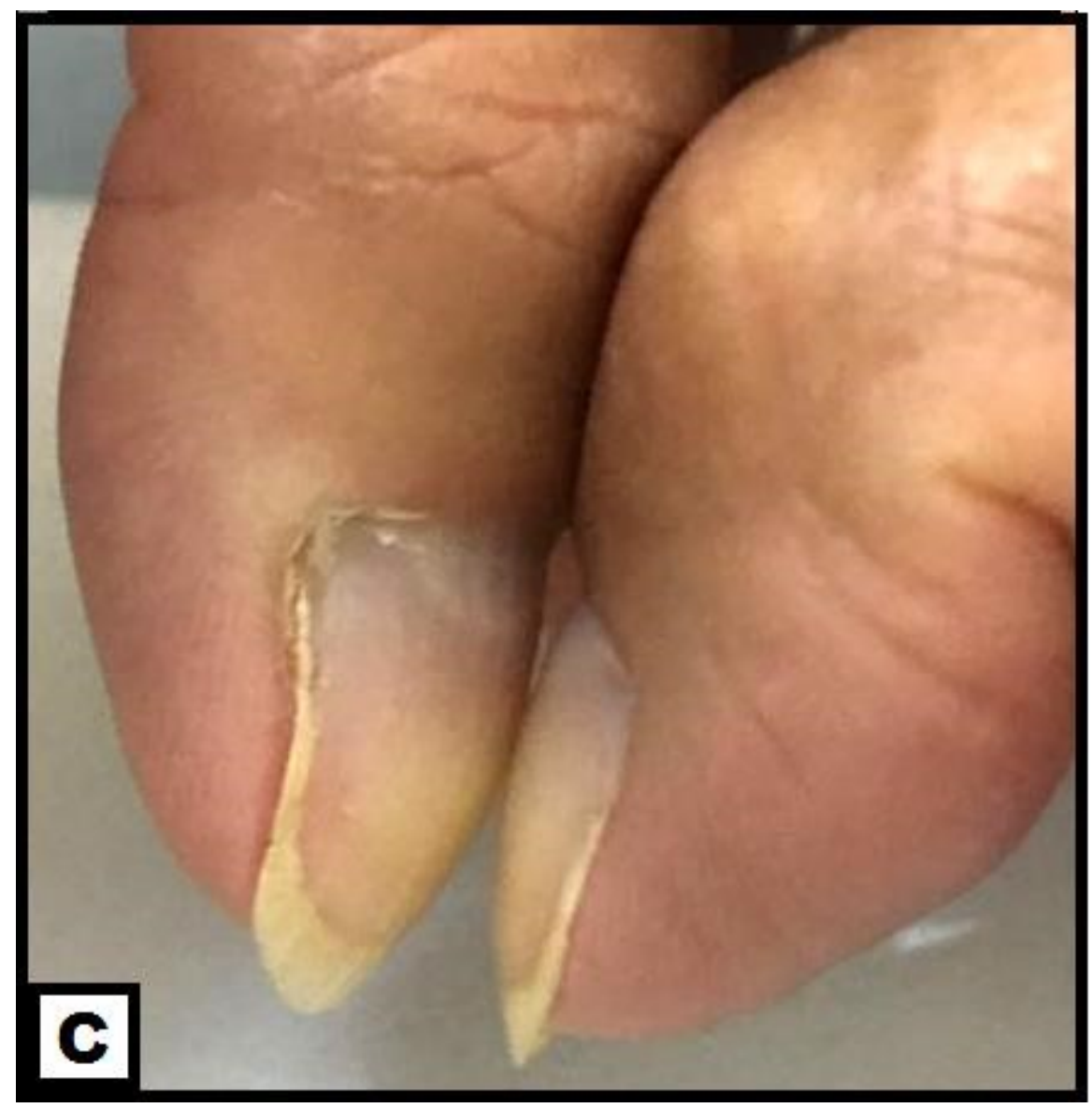

Figure C: Schamroth's sign

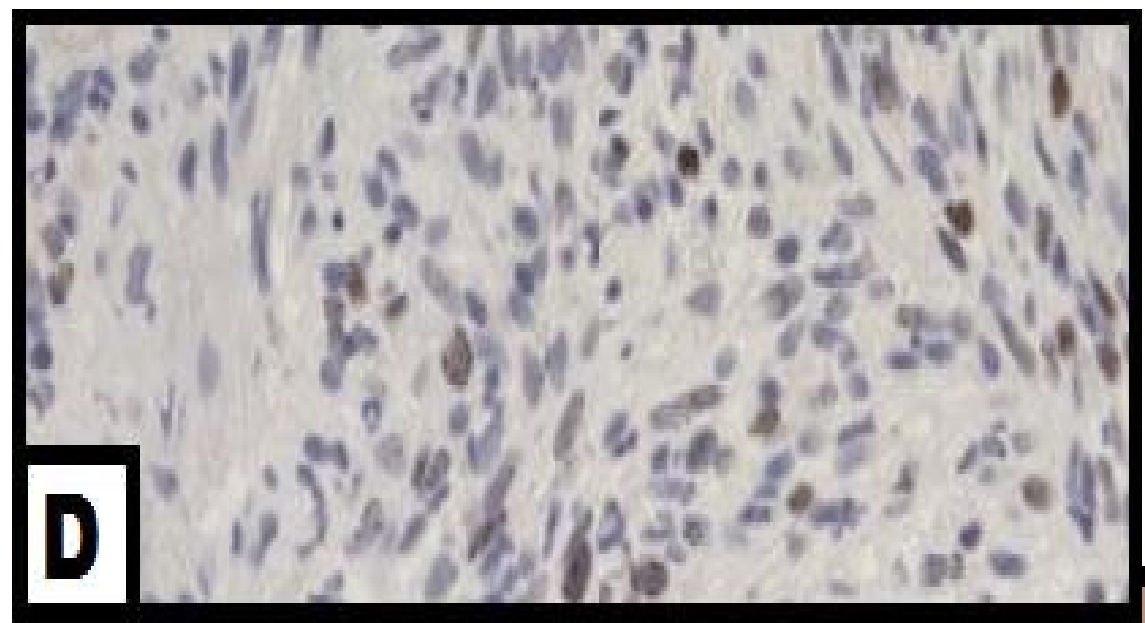

Figure D: Immunohistochemical stain of the stomach mucosa cells for Human Herpes Virus 8 


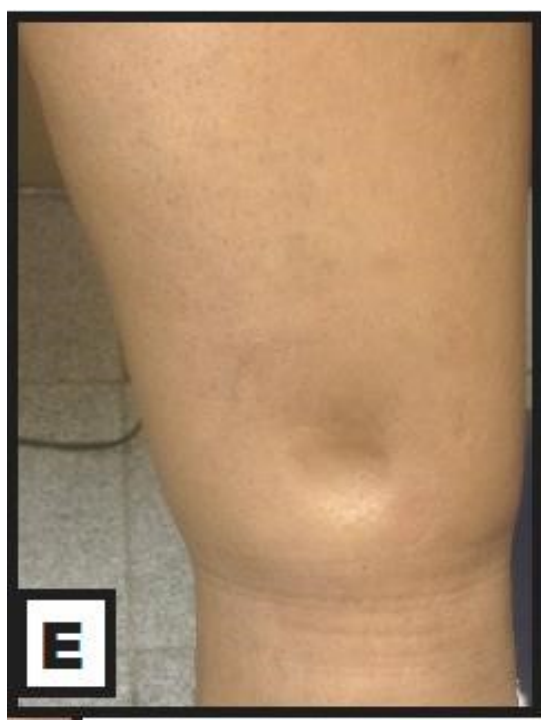

Figure E: Leg Edema

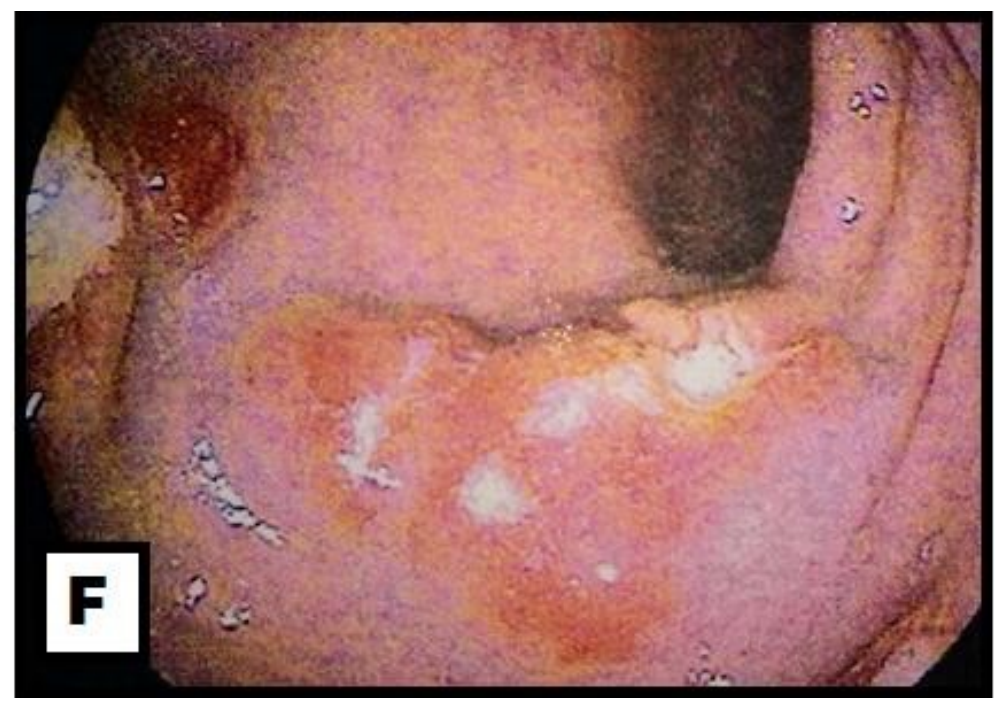

Figure F: Inflammatory sections of the ileum.

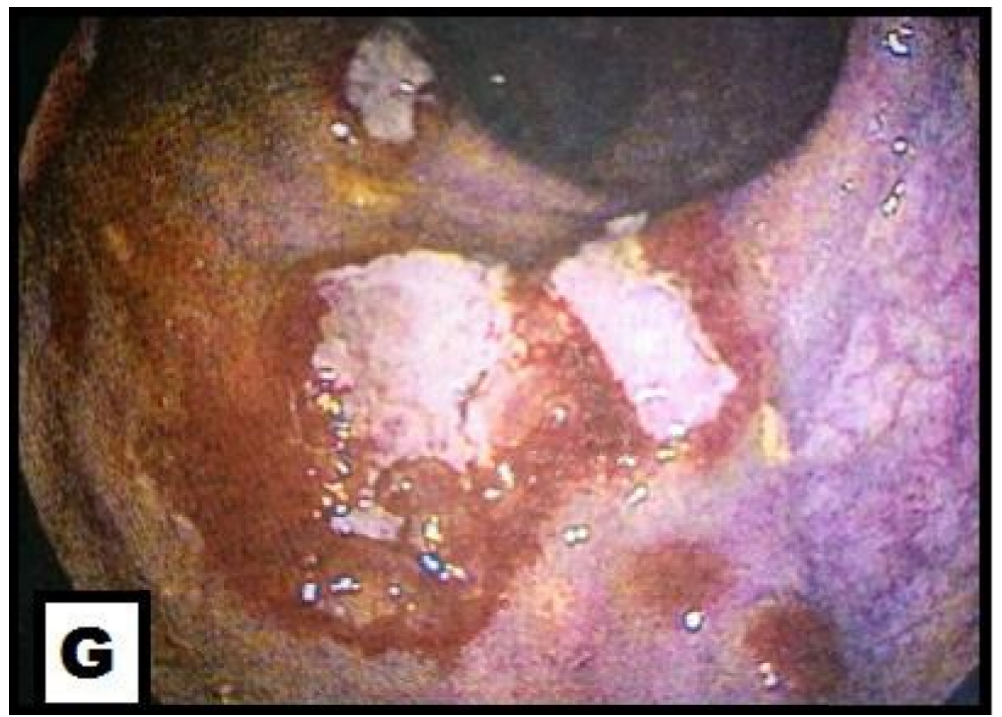

Figure G: Ulcerated and bleeding colon regions covered by fibrin

Rodrigues et al., Afro-Egypt J Infect Endem Dis 2017; 7(2): 66-72 http://mis.zu.edu.eg/ajied/home.aspx 


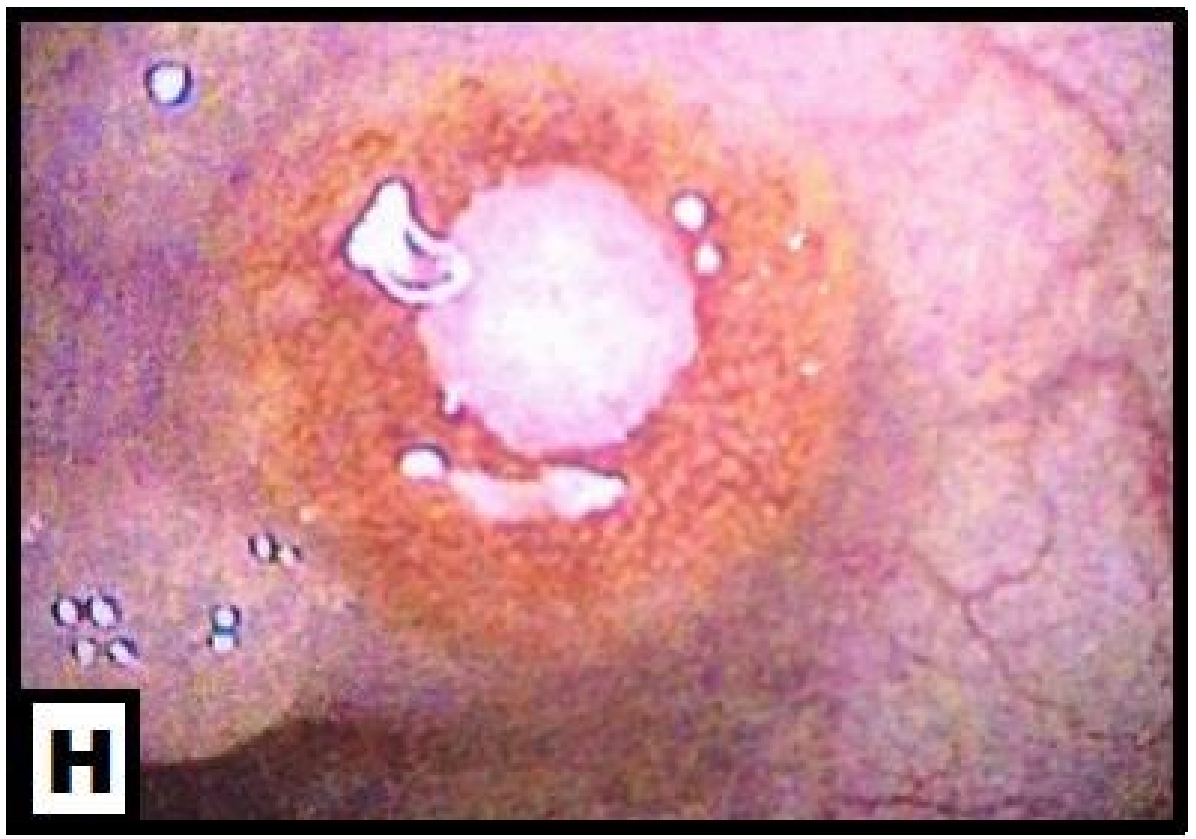

Figure H: Umbilicated rectal nodule

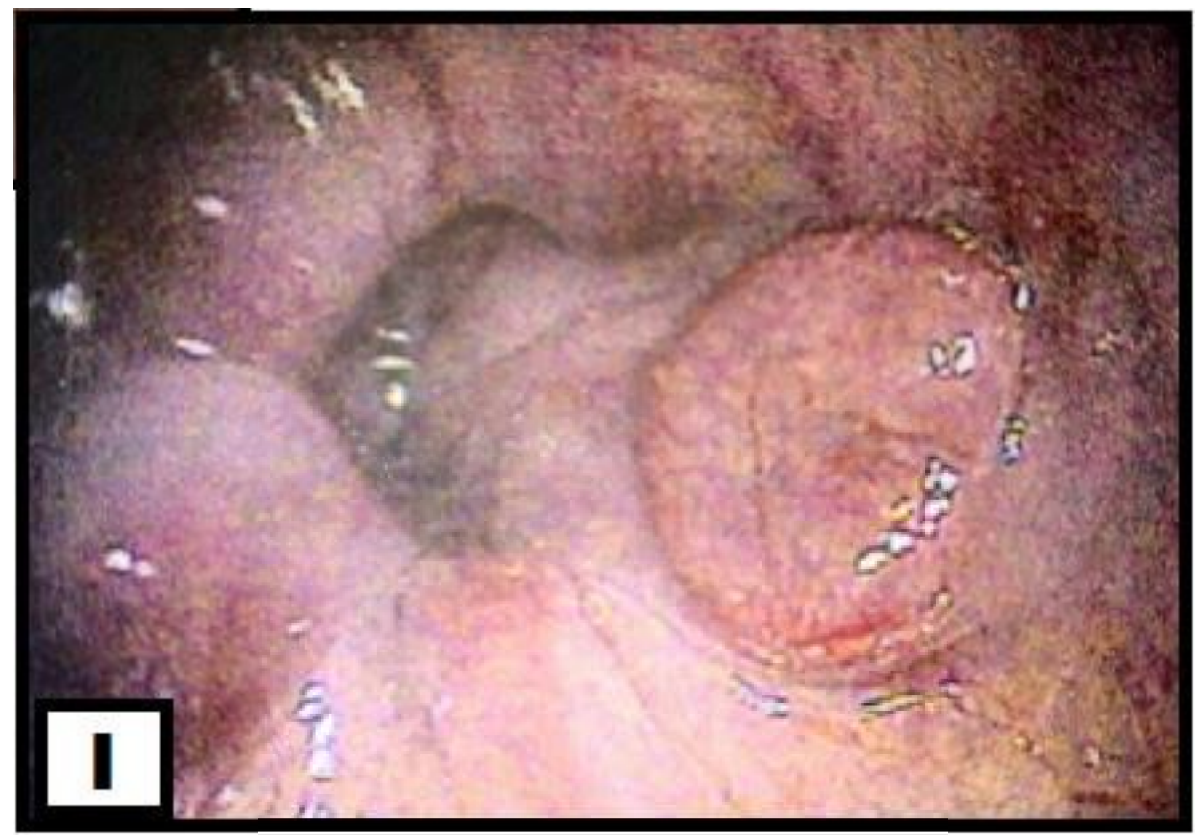

Figure I: Endoscopic image of the gastric antrum with Kaposi's sarcoma umbilicated lesions. 


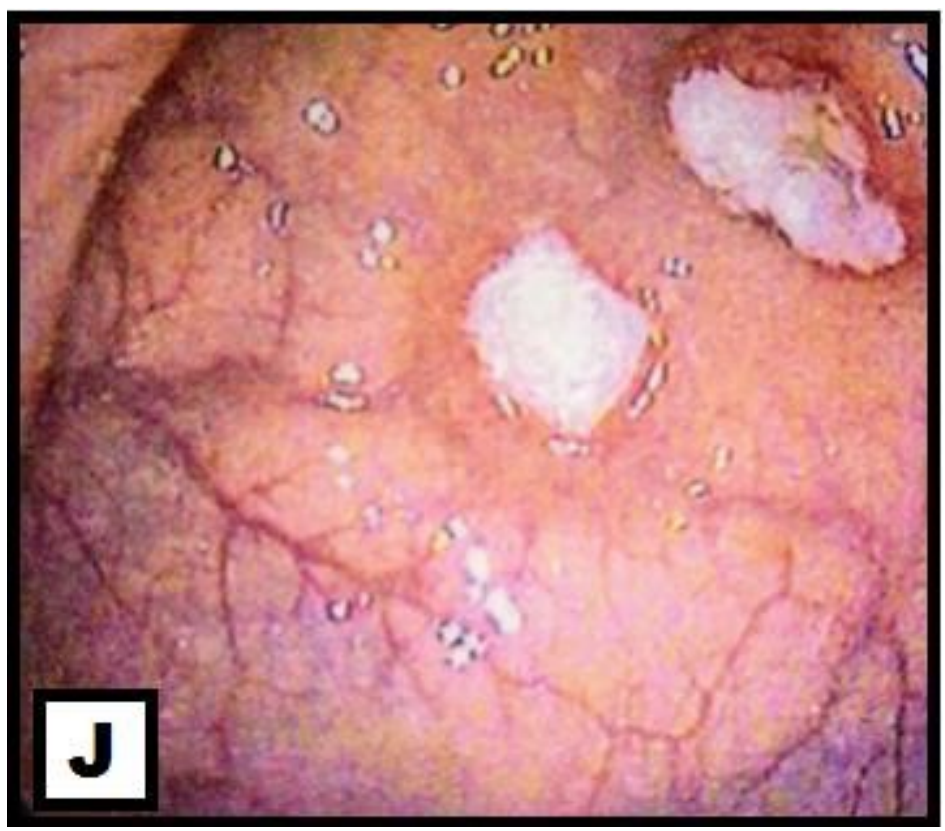

Figure J: Sigmoid colon ulcers.

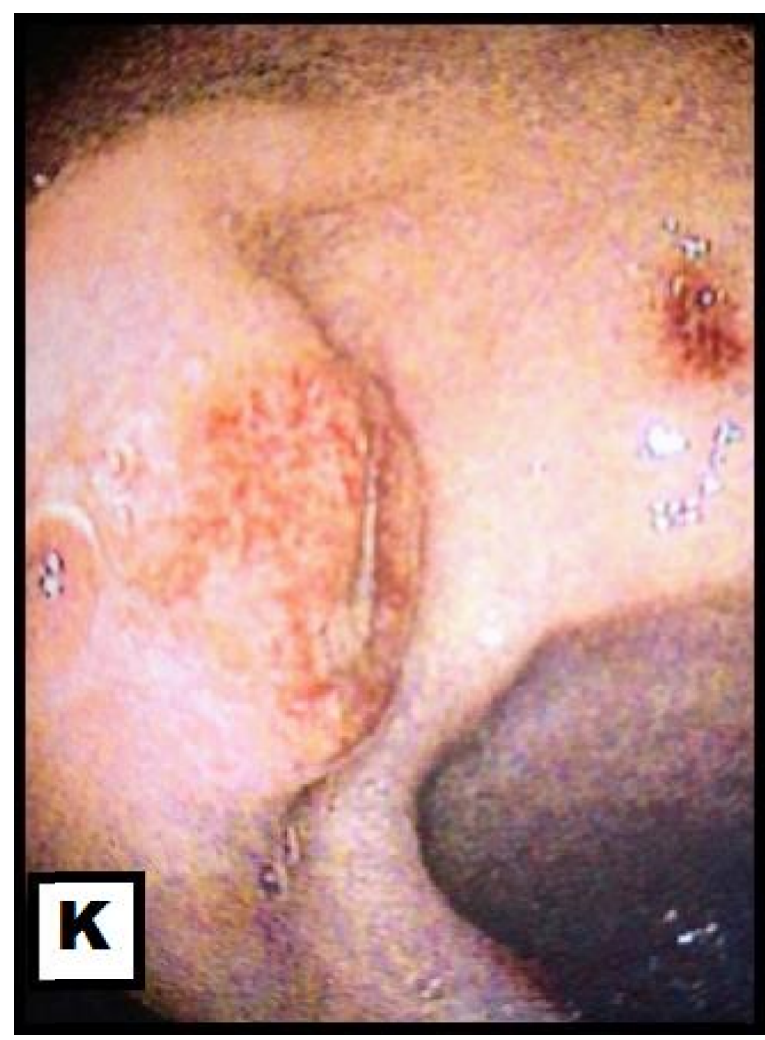

Figure K: Ulcerated duodenal nodule

Figure 1: A,B- Digital clubbing of the thumb. C- Schamroth's sign. D- Immunohistochemical stain of the stomach mucosa cells for human herpes virus 8 . E- Leg edema. F- Inflammatory sections of the ileum. G- Ulcerated and bleeding colon regions covered by fibrin. H- Umbilicated rectal nodule. IEndoscopic image of the gastric antrum with Kaposi's sarcoma umbilicated lesions. J- Sigmoid colon ulcers. K- Ulcerated gastric nodule. 


\section{REFERENCES}

1- Arora M, Goldberg EM. Kaposi Sarcoma Involving the Gastrointestinal Tract. Gastroenterol Hepatol. 2010; 6: 459-462.

2- Lee AJ, Brenner L, Mourad B, Monteiro C, Vega KJ, and Munoz JC. Gastrointestinal Kaposi's sarcoma: Case report and review of the literature. World J Gastrointest Pharmacol Ther. 2015; 6: 89-95.

3- Myers KA, Fraquhar DRE. Does this patient have clubbing? JAMA. 2001; 286: 341-347.
4- Cribier B, Mena ML, Rey D, Partisani M, Fabien V, Lang J, Grosshans E. Nail Changes in Patients Infected With Human Immunodeficiency Virus. A Prospective Controlled Study. Arch Dermatol. 1998; 134: 1216-1220.

5- Ddungu H, Johnson JL, Smieja M, Kizza HM. Digital clubbing in tuberculosis - relationship to HIV infection, extent of disease and hypoalbuminemia. BMC Infect Dis. 2006, 6:45.

6- Dever LL, Matta JS. Digital Clubbing in HIVInfected Patients: An Observational Study. AIDS PATIENT CARE and STDs. 2009; 23:19-22. 